Filol. Linguíst. Port., São Paulo, v. 19, n. 1, p. 33-56, jan./jun. 2017

http://dx.doi.org/10.11606/issn.2176-9419.v19i1p33-56

\title{
Apontamentos paleográficos e análise de indícios de mudança fonética em manuscrito setecentista de Minas Geraes
}

\author{
Paleographic remarks and phonetic change evidence \\ analysis concerning an $18^{\text {th }}$ century manuscript from Minas \\ Geraes
}

\author{
Soélis Teixeira do Prado Mendes* \\ Universidade Federal de Ouro Preto, Mariana, Minas Gerais, Brasil \\ Marcus Vinícius Pereira das Dores** \\ Universidade Federal de Minas Gerais, Belo Horizonte, Brasil \\ Matheus Freitas Gomes*** \\ Universidade Federal de Minas Gerais, Belo Horizonte, Brasil
}

\begin{abstract}
Resumo: Este artigo apresenta, de forma parcial, dados paleográficos de um manuscrito setecentista localizado no Arquivo Eclesiástico da Arquidiocese de Mariana (MG), do qual são extraídos e analisados casos que podem indiciar mudança fonética. Muitos desses casos ainda são recorrentes e atuantes no português brasileiro. Os dados aqui apresentados podem, de alguma forma, contribuir para os estudos etimológicos, já que o corpus analisado, transcrito com critérios filológicos, possui datação e localização.
\end{abstract}

Palavras-chave: Manuscrito. Edição diplomática. Paleografia. Mudanças fonéticas.

* Professora doutora do Departamento de Letras do Instituto de Ciências Humanas e Sociais, da Universidade Federal de Ouro Preto (UFOP), Campus Mariana. E-mail: soelisufop@gmail. com.

** Mestrando do Programa de Pós-Graduação em Estudos Linguísticos (PosLin), da Faculdade de Letras da Universidade Federal de Minas Gerais; bolsista CNPq. E-mail: marcusdores@, hotmail.com.

*** Mestrando do Programa de Pós-Graduação em Estudos Linguísticos (PosLin), da Faculdade de Letras da Universidade Federal de Minas Gerais; bolsista CAPES. E-mail: matheusfgomes@ outlook.com. 


\begin{abstract}
This article presents partial paleographic data from an 18th century manuscript from the Ecclesiastical Archive of the Archdiocese of Mariana (in the state of Minas Gerais, Brazil). Examples of possible phonetic change were extracted from this corpus and later analyzed. Many of these examples are still frequent and actively present in Brazilian Portuguese. The presented data may, to a certain extent, contribute to etymological studies since there is date and location for the analyzed corpus, which was transcribed according to philological criteria.
\end{abstract}

Keywords: Manuscript document. Diplomatic edition. Paleography. Phonetic change.

\title{
1 CONSIDERAÇÕES INICIAIS
}

As discussões aqui apresentadas fazem parte do projeto de pesquisa "O estudo da concordância variável (nominal e verbal) em manuscritos setecentistas de Minas Colonial”, edital 04/2015 PIBIC/CNPq/UFOP, desenvolvido no Departamento de Letras da Universidade Federal de Ouro Preto, sob coordenação e execução da Professora coautora deste texto, junto aos bolsistas também coautores.

Pretendemos, com este artigo, contribuir para os estudos da história do português brasileiro, em especial no que tange a indícios de mudanças fonéticas apreendidas por meio de pistas gráficas em um manuscrito setecentista de Minas Geraes. Os dados aqui apresentados podem, também, contribuir para os estudos etimológicos, tendo em vista que "[as] mudanças fonéticas norteiam, de algum modo, a certeza da etimologia e, apesar de não ser um método absolutamente dedutivo [...] é expediente imprescindível para separar as boas etimologias das más.” (Viaro, 2011, p. 131).

O manuscrito que nos serve de análise, denominado Auto de Sucreto, é parte constituinte do processo De Genere Vita et Moribus, do candidato à vida sacerdotal Francisco de Paula Meireles, o qual possui 195 fólios distribuídos em 4 maços. O documento aqui analisado faz parte do último maço e contém 5 fólios, entre recto e verso, numerados de 9 a 11. Esse processo pertence ao acervo do Arquivo Eclesiástico da Arquidiocese de Mariana (AEAM), Cúria Metropolitana.

$\mathrm{Na}$ primeira parte deste artigo, faremos alguns apontamentos paleográficos sobre o manuscrito sob análise para, em seguida, apresentarmos dados linguísticos relativos a indícios de mudança fonética que são extraídos desse material.

Mendes STP, Dores MVP, Gomes MF. Apontamentos paleográficos... 


\section{O PROCESSO DE GENERE, VITA ET MORIBUSE AS EDIÇÕES ADOTADAS}

Conforme se sabe, a Inquisição forçou judeus e mouros a professarem a fé no cristianismo e, ao mesmo tempo, criou-lhes uma barreira intransponível, pois os novos cristãos ${ }^{1}$ estavam marcados pelo pecado da sua origem. Em muitas ocasiões, era exigida limpeza de sangue, sobretudo para assumir encargos religiosos. Justamente para evitar a atribuição de cargos aos novos cristãos, todos os candidatos às ordens sacras eram submetidos à investigação genealógica.

A partir do século XVI, com a promulgação do Breve De puritate sanguinis, do papa Urbano VIII, para qualquer cargo pretendido, todos os candidatos deveriam submeter-se aos processos de habilitação De genere, vita et moribus (sobre a origem, vida e costumes), por meio dos quais se comprovavam a "pureza de sangue e costumes" e a existência de uma renda mínima (Villalta, 2007).

Os processos para ingresso à vida sacerdotal eram demorados, justamente porque exigiam testemunhos e comprovações de diversas pessoas. Ao final, os candidatos que passavam por esse rigoroso processo eclesiástico dividiam as honras com os seus familiares: "[as] famílias, durante o Período Colonial, mantiveram a prática de encaminhar ao menos um de seus filhos ao sacerdócio, que se apresentava como uma carreira almejada [...] para os que provinham das "boas famílias"' (Villalta, 2007, p. 28). Ter entre os seus familiares pelo menos um sacerdote com a declaração de boas origens era um glorioso status social. Segundo Carneiro (2005, p. 4950), a distinção entre cristãos-novos e cristãos-velhos persistiu até 1773 , quando o marquês de Pombal a aboliu, por decreto. Mesmo assim, por muitos anos continuou o temor de que alguma pessoa de sangue impuro se habilitasse ao sacerdócio.

A edição de textos pretéritos tem um papel histórico-cultural diretamente ligado à propagação da memória de certos grupos entre distintos públicos - dos mais leigos aos mais versados - dependendo da modalidade de edição adotada. Existem, conforme Spina (1977), diversas maneiras de se editar um texto: a fac-similar ou mecânica, a diplomática, a semidiplomática ou paleográfica e a edição crítica. A opção por uma ou mais

1 Novos cristãos, cristãos novos, ou marranos: termos utilizados para designar pessoas recém-convertidas ao cristianismo ou pessoas ascendentes de judeus ou de outra raça.

Mendes STP, Dores MVP, Gomes MF. Apontamentos paleográficos... 
de uma dessas dependerá de qual é o leitor almejado, pois dificilmente uma mesma edição pode ser adequada a um ou a outro público indistintamente (Cambraia, 2005).

Como nosso interesse é realizar uma edição que tenha como público o pesquisador da área da Linguística Histórica, que pretende fazer uso de corpora nas análises das mudanças linguísticas de longa duração, a opção recai sobre a edição diplomática, que visa à atualização tipográfica do texto, mas fazendo o mínimo de intervenção possível, ou seja, todos os aspectos do testemunho e do texto são mantidos bem próximos ao original. Para o presente artigo, apresentamos esse tipo de edição e a fac-similar, que é a reprodução digital do manuscrito.

Em função dos limites deste artigo, apenas apresentaremos, de forma parcial, a imagem do manuscrito sob análise e sua respectiva transcrição, feita com base nas normas propostas por Mendes (2008) que, por sua vez, baseou-se em Cambraia et al. (2001).

a) A transcrição procurará ser fiel ao texto original;

b) Não serão desdobradas as abreviaturas;

c) Não será estabelecida fronteira de palavras que venham escritas juntas nem se introduzirá hífen ou apóstrofo onde não houver (ex: "deNosso"; “deJulho"; “emvirtude”);

d) Serão mantidas a pontuação e acentuação originais;

e) Será respeitado o emprego de maiúsculas e minúsculas como se apresentam no original;

f) Quando a leitura paleográfica de uma palavra for duvidosa, a sua transcrição será feita entre parênteses: ( );

g) São transcritos na sua forma original os numerais, tanto indo-arábicos como romanos;

h) Serão apontadas antes da transcrição as intervenções de terceiros no documento original, bem como o seu estado de conservação; 
i) Serão informadas em nota as anotações de outro punho, as alterações e os borrões de tinta;

j) Serão transcritos como pontos dentro de colchetes precedidos pela cruz † os caracteres cuja leitura for impossível, sendo que o número de pontos é o de caracteres não legíveis (Cambraia, 2005, p. 128). Entretanto, quando não for possível identificar esse número, apenas será registrada a cruz;

k) Palavra(s) danificada(s) por corrosão de tinta, umidade, rasgaduras ou corroídas por insetos ou outros será(ão) indicada(s) entre colchetes, assim: [corroída] ou [corroídas]. Em se tratando de um trecho de maior extensão danificado pelo mesmo motivo, será indicada entre colchetes a expressão [corroída + de 1 linha];

l) A divisão das linhas do documento original será preservada na edição, ao longo do texto, pela marca de uma barra vertical: | entre as linhas. A mudança de fólio será indicada com duas barras verticais: ||;

m) As páginas serão numeradas de acordo com o documento original, indicadas, nesse caso, entre duas barras verticais, além de apresentar o estado do fólio. Exemplos: || fl.1r.||; | fl.1 v. ||;

n) Se o original não for numerado ou estiver ilegível sua numeração, os números acrescentados serão impressos entre colchetes, indicando-lhes o estado do fólio. Exemplos: [fl.1 r.]; [fl.1v.];

o) $\mathrm{Na}$ edição, as linhas serão numeradas de 5 em 5 a partir da quinta, considerando, inclusive, o título. Essa numeração será colocada à margem direita da mancha, à esquerda do leitor. Será feita de maneira contínua por documento;

p) As assinaturas simples ou as rubricas do punho de quem assina serão sublinhadas. Já aquelas marcadas com um X, além de se apresentarem sublinhadas, serão marcadas pelo tipo itálico. Exemplos: "Joaquim Pinto" e De Fructuoso+ Pra. de Souza|; 
q) Os espaços em branco deixados pelo escrivão serão assim identificados: [espaço];

r) Os fragmentos de frases ou palavras que foram suprimidos pelo escrivão serão indicados em nota.

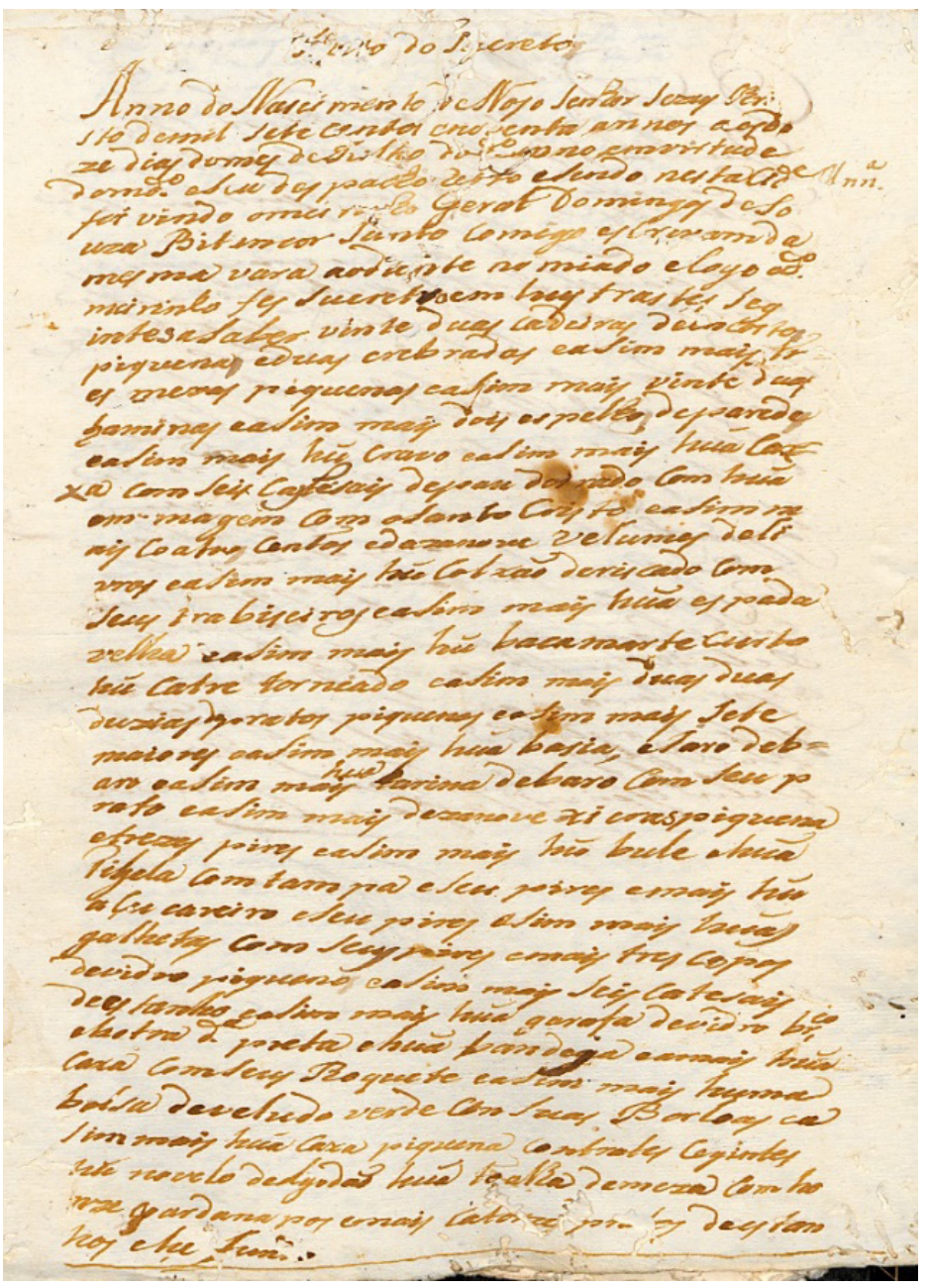

Figura 1 - Fac-símile do fl. 9v, 4. ${ }^{\circ}$ maço. Fonte: AEAM

Mendes STP, Dores MVP, Gomes MF. Apontamentos paleográficos... 


\section{||fl.9v.|| Ato do S[†..]creto | Anno do Nascimento deNoso Senhor Jezus Cri} sto demil sete centos enoventa annos aosdo | ze dias domes deJulho $\left(\mathrm{dod}^{\circ}\right)$ anno emvirtude | domd. ${ }^{\mathrm{e}}$ es (se) des pacho vito esendo nes tacideMnn. ${ }^{\mathrm{a} 2}$ | foi vindo omei rinho GeralDomingos deSo | uza Bitencor Junto Comigo escrevam da | mesma vara

5 aodiante no miado elogo od. ${ }^{\circ} \mid$ meirinho fez sucretro em hus tras tes seg | intes asaber vinte duas cadeiras de(e)ncostar | piquena eduas crebradas easim mais tr | es mezas piquenas easim mais vinte duas | haminas easim mais dois espelhos deparede | easim mais hū cravo easim mais huã Cax | xa com seis castesais depau doirado com huã | em[†.]magem com osanto Cristo easim $\mathrm{m}$ | ais coatro centos edazanove velumes deli |

10 vros easim mais hū colxão deriscado com | seus trabiseiros easim mais huã espada | velha easim mais hū bacamarte curto | hū catre torniado easim mais duas duas | duzias depratos piquenos easim mais sete $\mid$ maiores easim mais huã basia eJaro deb $=\mid$ aro easim mais hua ${ }^{3}$ tarina de baro com seu $\mathrm{p}$ | rato easim mais dezanove xi cras piquena | etrezes pires easim mais hū bule e huã | tilgela com tampa e seu pires emais hū | açucareiro

15 eseu pires easim mais huãs | galhetas com seus pires emais tres copos | devidro piqueno easim mais seis catesais | de estanho easim mais huã garafa devidro br ${ }^{c o} \mid$ ehotra d. ${ }^{a}$ preta ehuã bandeja eamais huã | caxa comseus Roquete easim mais huma | bolsa develudo verde con suas Borloas ea | sim mais huã caxa piquena contrates cegintes | hū novelo dealgodaõ huã toalha demeza com ho $\mid$ nze $(\mathrm{g})^{4}$ oardanapos emais catorze pr(at)os

20 deestan | hos ehu fundo ||

\subsection{Alguns apontamentos paleográficos}

A Filologia e a Paleografia entrelaçam-se no processo de edição de textos, uma vez que dispõem de aparatos científicos e metodológicos para que a transcrição possa ser feita de acordo com a finalidade pretendida. Em relação à modalidade escrita, o manuscrito nos lança à investigação de alguns aspectos.

\subsubsection{O alfabeto do punho}

A edição de textos manuscritos antigos é um processo lento e criterioso, pois, além do estado de conservação do documento que na maioria das vezes prejudica a leitura, é preciso habituar-se ao tipo de escrita. Um recurso que

2 Não há separação de fronteira entre as duas abreviaturas. O vocábulo abreviado Mnn encontra-se à margem direita, fora da mancha escrita.

3 No documento, esta palavra está escrita acima da anterior, a saber, "mais".

4 No documento, há um borrão na parte inferior do grafema inicial desta palavra, e pressupomos se tratar de um $/ \mathrm{g} /$.

Mendes STP, Dores MVP, Gomes MF. Apontamentos paleográficos... 
auxilia muito nesse processo de edição é a composição de um alfabeto do punho que grafou o texto (Fachin, 2009, p. 261). A seguir, apresentamos o alfabeto do punho do escrivão Antônio Dias Braga, autor alógrafo ${ }^{5}$ e autógrafo do Auto de Sequestro de Francisco de Paula Meireles (1790).

Tabela 1 - Alfabeto do punho de Antônio Dias Braga

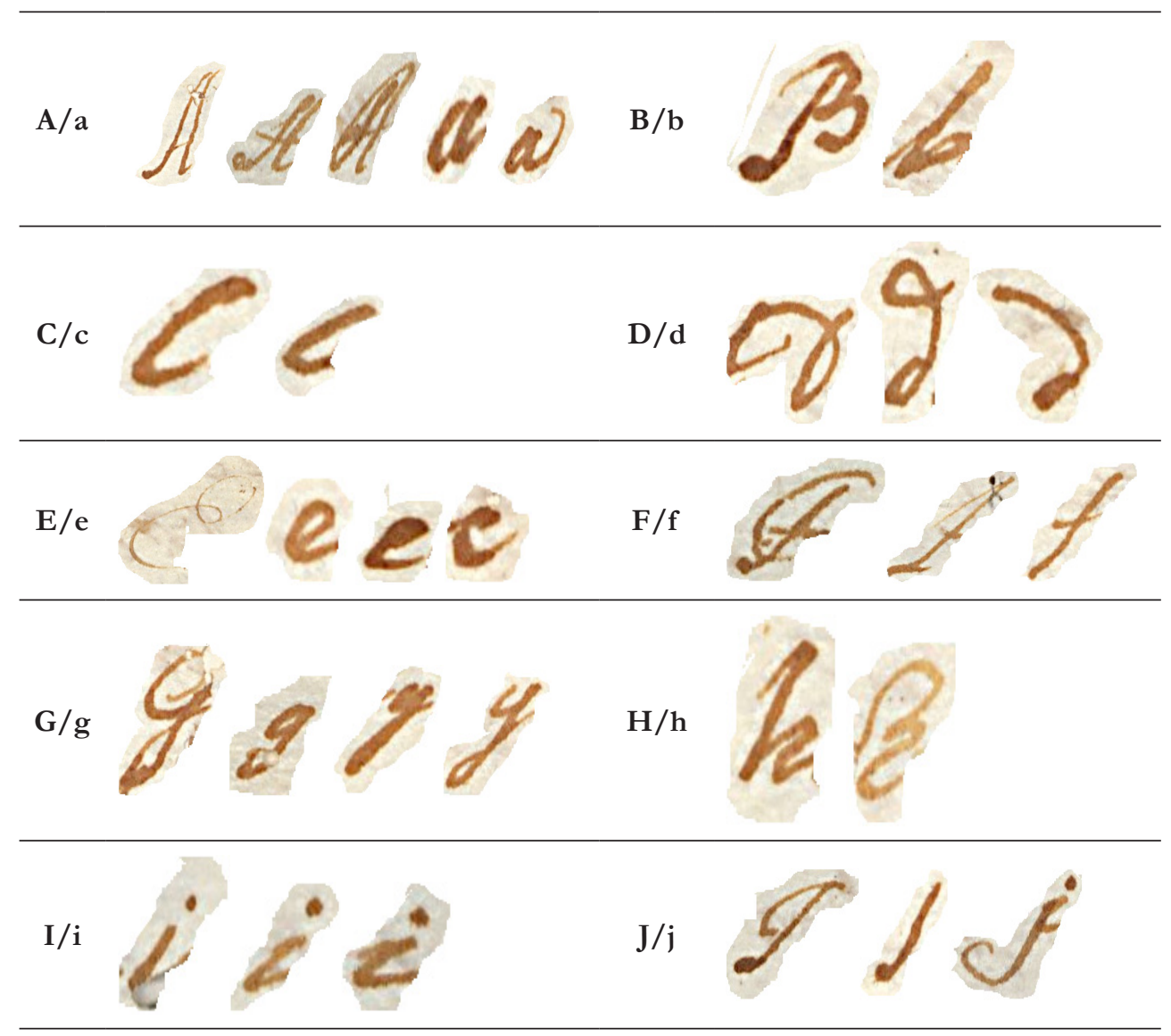

5 O escrivão Antônio Dias Braga é autor alógrafo da parte formulaica do documento, visto que nela ele reproduz a tradição desse tipo de gênero, não sendo, portanto, o autor intelectual do texto. No que diz respeito ao restante do documento, depreende-se tratar-se de texto autógrafo. 


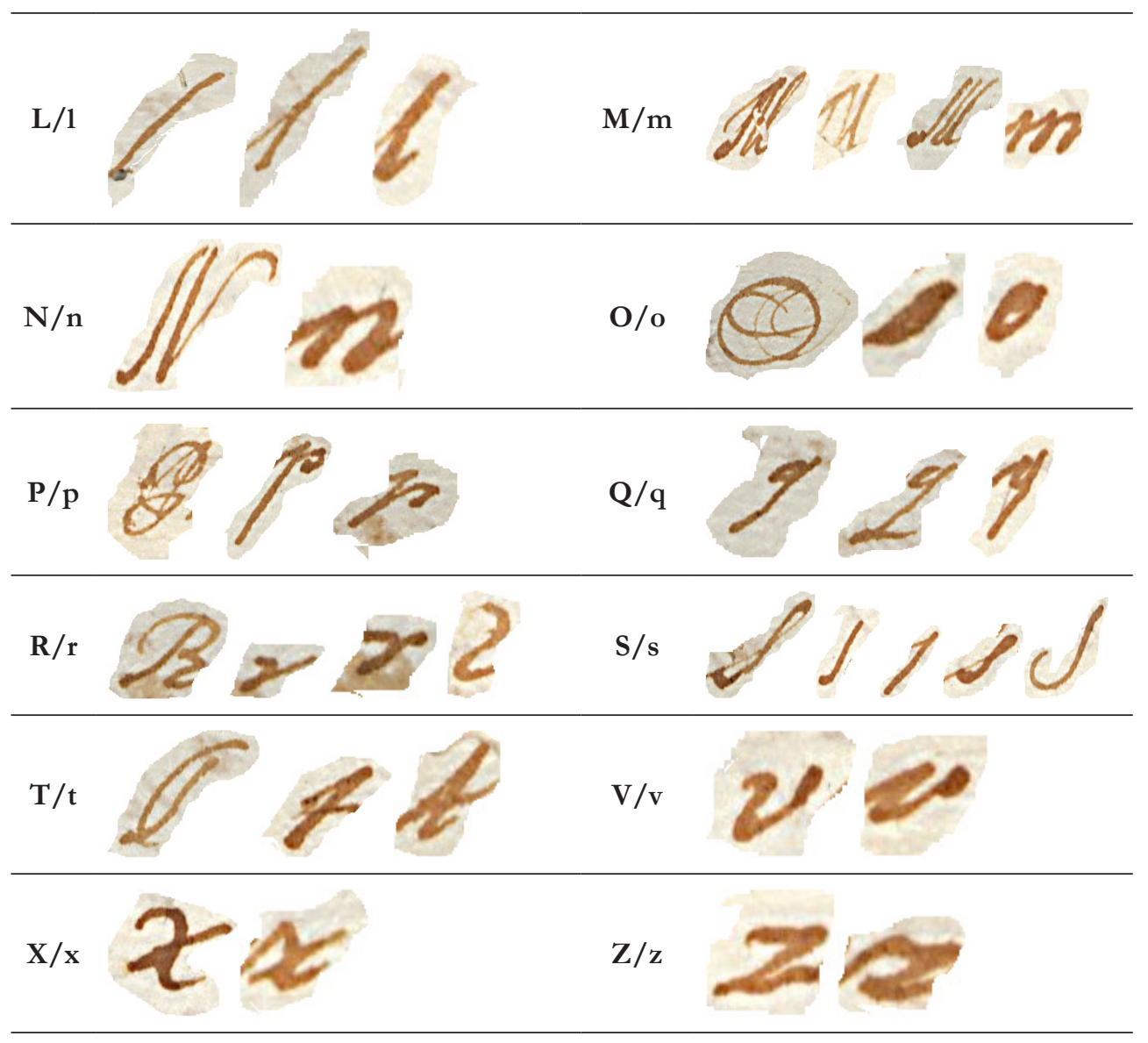

\subsubsection{Abreviaturas}

Embora a edição escolhida seja mais conservadora e, portanto, as abreviaturas não tenham sido desfeitas, gostaríamos de apresentar os tipos que o testemunho possui. Segundo Flexor (2008), as abreviaturas são mecanismos utilizados com a finalidade de diminuir o tamanho de uma palavra poupando, assim, material (papel e tinta) e tempo de escrita. Entretanto, o fato de as abreviaturas demandarem maior ou menor tempo do escriba não é uma unanimidade. Isso porque, segundo Stiennon (1973 apud Duchowny et al., 2014), tais recursos podem ocupar espaço, tempo e atenção de forma igual ou superior ao que o escriba dedica à grafia completa da palavra. 
Conforme Flexor (2008, p. 12), nos documentos luso-brasileiros "não existiam regras de abreviação", mas alguns pesquisadores da área (Chaves, 2006; Flexor, 2008; Megale, Toledo Neto, 2005; Spina, 1977) propõem algumas classificações para as abreviaturas: por sigla, por letra sobrescrita, por síncope, por suspensão, por sinal especial e por nota tironiana. Duchowny et al. (2014) e Duchowny et al. (2015), por sua vez, além dessas classificações, propõem outras como: por sinal geral, abreviatura mista, numéricas e contração.

As poucas abreviaturas encontradas no Auto de Sequestro ${ }^{6}$ se enquadram apenas em duas das classificações apresentadas, conforme será exposto a seguir.

\subsubsection{Abreviatura por letra sobrescrita ${ }^{7}$}

Tabela 2 - Abreviaturas por letra sobrescrita

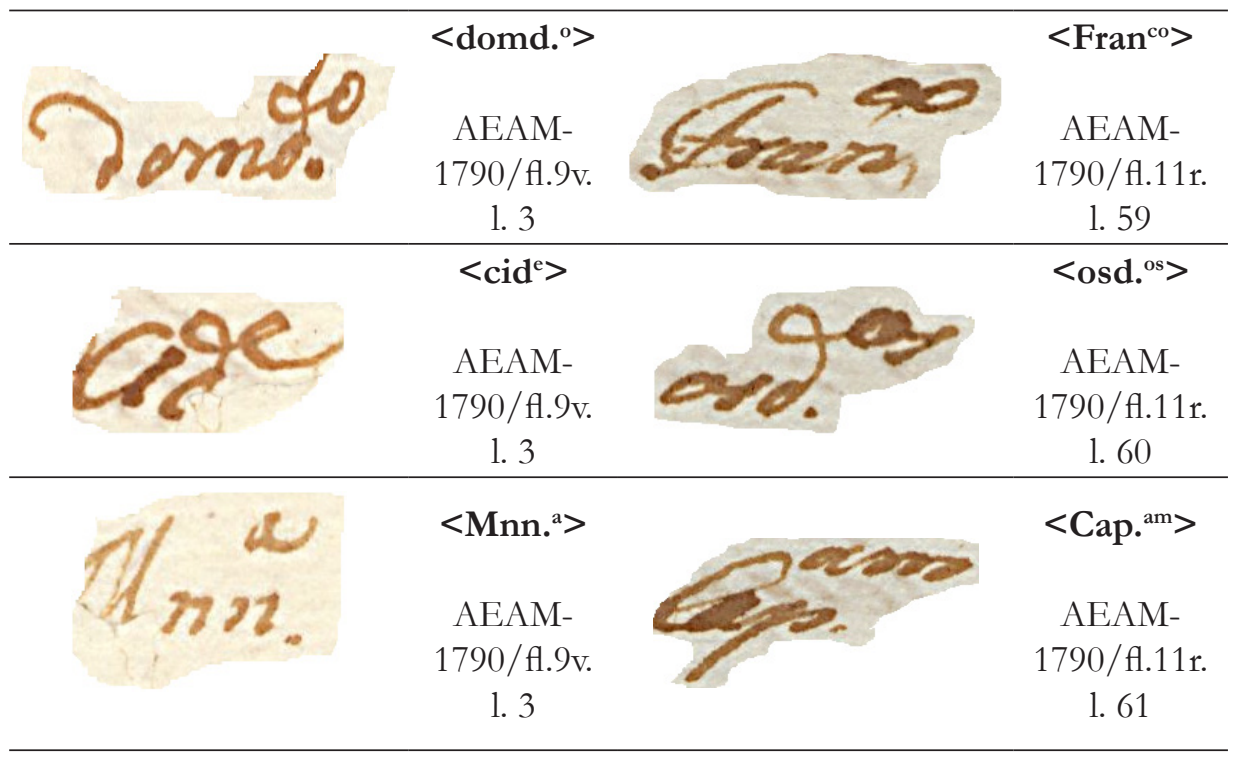

6 AEAM -1790 / fl. 9v a 11 r.

7 Nesse tipo de abreviatura também ocorre o processo de síncope.

Mendes STP, Dores MVP, Gomes MF. Apontamentos paleográficos... 


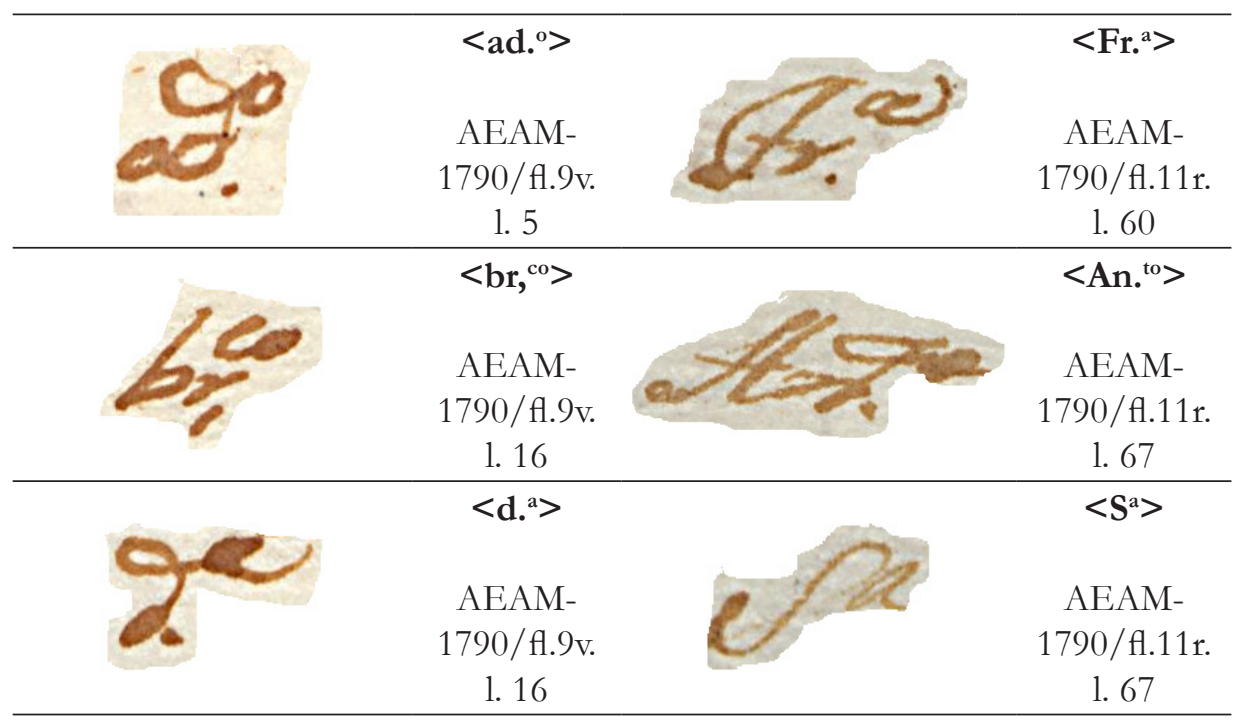

\subsubsection{Abreviatura por sinal geral}

Tabela 3 - Abreviatura por sinal geral

AEAM-
$1790 /$ fl.11r.
1.61

\subsubsection{Consoantes dobradas}

A ocorrência desse tipo de fenômeno justifica-se pelo fato de não existir um padrão uniforme de ortografia no período de escrita do documento. A presença das letras consoantes dobradas faz referência ao período pseudoetimológico ${ }^{8}$ da história da ortografia portuguesa.

8 "Período Pseudo-Etimológico: Inicia-se no século XVI e vai até o ano de 1904, em que aparece a Ortografia Nacional de Gonçalves Viana. O que caracteriza este período é o emprego de consoantes geminadas e insonoras, de grupos consonantais impropriamente chamados gregos, de letras como o y, k e w, sempre que ocorriam nas palavras originárias." (Coutinho, 1976, p. 107). 
Tabela 4 - Palavras grafadas com consoantes dobradas

\begin{tabular}{|c|c|c|}
\hline tro. & $<$ Anno $>$ & $\begin{array}{c}\text { AEAM- } \\
\text { 1790/fl.9v. } \\
1.1\end{array}$ \\
\hline & $<$ annos $>$ & $\begin{array}{c}\text { AEAM- } \\
\text { 1790/fl.9v. } \\
1.2\end{array}$ \\
\hline 2 & $<$ fivellas $>$ & $\begin{array}{c}\text { AEAM- } \\
\text { 1790/fl.10r. } \\
\text { 1. } 26\end{array}$ \\
\hline
\end{tabular}

\subsubsection{Ausência de fronteira entre palavras}

É muito comum em documentos manuscritos antigos a ausência de fronteiras entre algumas palavras. Uma das explicações para essa ocorrência pode ser atribuída à necessidade de agilizar o processo de escrita, principalmente por se tratar de letras cursivas, e/ou economizar material, uma vez que o ato de levantar a pena da superfície do papel resulta em maior gasto de tempo, de tinta e do próprio suporte utilizado para escrever. Outra explicação para essa ausência poderia ser a presença da oralidade na escrita, ou seja, o escriba registraria as palavras ou conjunto de palavras tal como as pronunciava, sem indicar pausa entre uma e outra, como uma espécie de registro escrito da palavra fonológica.

Ora, de acordo com Bisol (1999, p. 233), entende-se por palavra fonológica o constituinte que apresenta um acento primário, ou seja, uma sílaba mais proeminente que as demais. Dessa forma, conforme complementa a autora, palavras que não possuem acento próprio são dependentes, no português brasileiro, de outra palavra de conteúdo. Essa relação é denominada grupo clítico, isto é, uma unidade prosódica composta por um ou mais clíticos e uma palavra de conteúdo, que contém o acento, como é o caso de fala-se e te espero, em que tanto te quanto se não possuem acento e formam com os respectivos verbos fala e espero um vocábulo fonológico. No entanto, não se verifica, no documento analisado, uma representação categórica de todos os casos de grupos clíticos grafados sem demarcação de fronteiras de palavras, conforme apresentado a seguir. 
(1) Ato do S[†..]creto | Anno do Nascimento deNoso Senhor Jezus (AEAM-1790/f1.9v. 1. 1)

(2) ... huã Cax | xa com seis castesais depau doirado com huã ... (AEAM-1790/fl.9v. 1. 8)

(3) ... mais hua ${ }^{9}$ tarina de baro (AEAM-1790/fl.9v. 1. 13)

Como a discussão desse assunto não é o tema do presente artigo, vamos nos restringir a essas considerações, apontando para a necessidade de pesquisar mais sobre essa questão, a fim de averiguar mais a fundo a relação entre conceito de palavra fonológica e esse tipo de escrita.

Seguem alguns exemplos retirados do manuscrito analisado nos quais não há fronteira entre palavras registrada pela escrita:

Tabela 5 - Palavras grafadas sem fronteiras

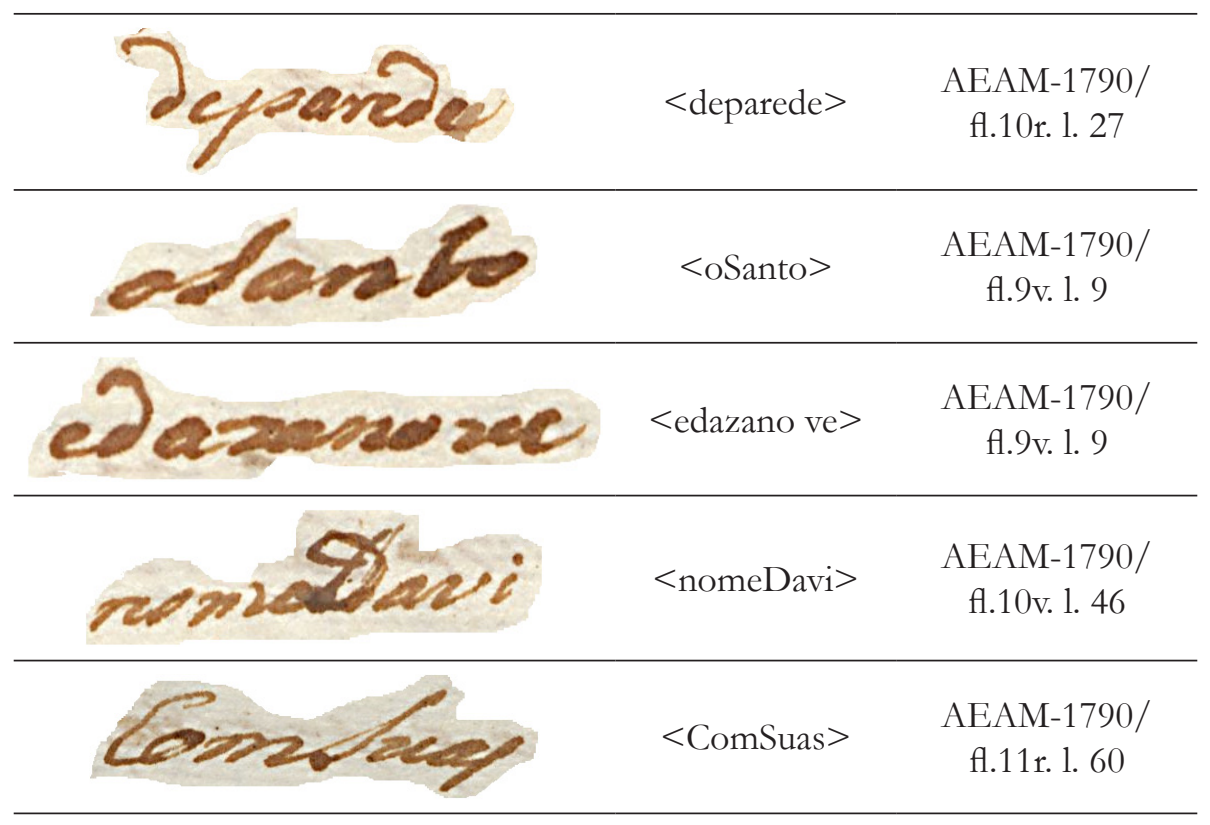

9 No documento, esta palavra está escrita acima da anterior, a saber, "mais".

Mendes STP, Dores MVP, Gomes MF. Apontamentos paleográficos... 


\section{ANÁLISE DE INDÍCIOS DE MUDANÇAS FONÉTICAS}

Os dados manifestos no manuscrito evidenciam casos de variação sociolinguística por meio da ocorrência de formas distintas da ortografia atual - que serve como parâmetro para o levantamento feito neste trabalho das mudanças fonéticas para esses dados -, e atuam como fomento para tais fenômenos. Uma vez que se considera a forma ortográfica atual como parâmetro de comparação, os dados levantados não denunciam apenas formas pretéritas remetendo a formas mais antigas das palavras ou ao seu étimo, mas também a formas em variação no português brasileiro atual.

Para discussão de casos de mudanças fonéticas, nomeadas em muitas gramáticas históricas como metaplasmos, fazemos uso da obra Etimologia, de Mário Eduardo Viaro, por apresentar tanto definições bastante elucidativas quanto a casos do português brasileiro contemporâneo, não se restringindo, portanto, a sincronias pretéritas.

Com relação à etimologia, Viaro (2011, p. 131) constata que "[a]s mudanças fonéticas norteiam, de algum modo, a certeza da etimologia e [...] é expediente imprescindível para separar as boas etimologias das más". Dessa maneira, apresentam-se casos extraídos do manuscrito em que a forma escrita, como representação de uma possível produção oral, pode atuar como modo de resgate à etimologia.

Já quanto a dados que evidenciam a existência de variações encontradas atualmente no português brasileiro e também presentes no século XVIII, é possível afirmar que tais variantes não são historicamente recentes, como o falante comum possa crer.

Os tipos de mudança fonética foram selecionados a partir das ocorrências encontradas no documento sob análise, os quais foram agrupados de acordo com essas mudanças. Adiante, cada tipo de mudança será apresentado e discutido de forma detalhada e exemplificada.

\subsection{Adições}

Dos três tipos apresentados por Viaro (2011), no manuscrito, localizamos apenas a epêntese, para cuja definição o autor parte de seu étimo grego de significado "intercalação". Apesar de salientar o uso do termo - em especial nos estudos de Fonologia - para denominar "qualquer 
tipo de adição", usado para definir também fenômenos de próstese e de paragoge, o autor restringe o fenômeno à adição de sons em posição medial no vocábulo.

A seguir apresentamos cada uma das ocorrências localizadas no testemunho:

\subsubsection{Epêntese de “ $r$ "}

No documento, são encontrados três tipos de inserção de “ $\mathrm{r}$ ” em posição medial de vocábulos. Todos apresentam na sílaba em questão o fonema / f/ em posição pós-consonantal, conforme (5) "crebrada" e (7) "pratro" - ou pós-vocálica: (6) "corberto". É possível propor que, em certa medida, esse / $\mathrm{f} /$ atua como influência significante para a inserção do "segundo r" nas palavras.

Outra ocorrência de inserção de "r" se dá na segunda sílaba da palavra "sucretro" (sequestro), que intitula o ato, e ocorre seis vezes de diferentes formas no texto. Entre essas ocorrências, apenas uma se configura como epêntese, uma vez que nas demais o " $r$ " na segunda sílaba é o único na palavra, o que define um fenômeno de metátese, apresentado mais à frente.

(4) sucretro (AEAM-1790/fl.9v. 1. 5)

(5) crebrada (AEAM-1790/fl.9v. 1. 6)

(6) corberto (AEAM-1790/fl.10v. 1. 42)

(7) pratro (AEAM-1790/f1.9v. 1.44 e 45)

\subsubsection{Epêntese de semivogal: ditongação}

Viaro (2011, p. 134) chama a atenção para o fato de a ocorrência de uma epêntese da semivogal /i/ precedente a /s/ em final ser muito comum em variantes do português brasileiro atual, tais como em: "arroz $>$ [a'xojs], capaz $>$ [ka'pajs], voz > ['vojs], freguês > [fre'gejs]”. Entretanto, no manuscrito analisado, não localizamos a epêntese da semivogal /i/ nesse contexto, mas antes de um /d/ em posição medial, conforme:

(8) Reide (AEAM-1790/fl.11r. 1. 5) 


\subsubsection{Epêntese de "l"}

O terceiro tipo de inserção de som concerne ao /1/ pós-vocálico na sílaba, como é o caso de "tilgela", em que o fonema é adicionado no meio de vocábulo. e de "baul", em fim de palavra. Aventamos a hipótese de essa epêntese em final de palavra ser um caso de hipercorreção com base no uso oral, em que a consoante líquida lateral em fim de sílaba pudesse ser pronunciada com uma lateral velarizada.

(9) tilgela (AEAM-1790/fl.9v. 1. 13)

(10) baul (AEAM-1790/fl.10v. l)

\subsection{Subtrações}

Trata-se do apagamento de sons na palavra e, segundo Viaro, o tipo mais recorrente é a síncope e seus subtipos; o que se verifica no manuscrito analisado, conforme:

\subsubsection{Síncope}

Por síncope, entende-se a eliminação de algum som interno à palavra. A partir da definição de Viaro, foram considerados fenômenos de monotongação, eliminação de sílaba completa ou de sons vocálicos e, nesse caso, consonantais.

\subsubsection{Síncope da pós-tônica}

A síncope da primeira pós-tônica, ou seja, sua subtração, em palavras proparoxítonas, transformando-nas em paroxítonas durante a passagem do latim para o português, é apresentada por Viaro (2011, p. 143) como um fenômeno amplamente recorrente. A ocorrência encontrada no manuscrito é, inclusive, utilizada pelo autor como exemplo. A produção de (11) "xicras" como paroxítona pela queda do primeiro "a" pós-tônico é exaltada junto a outros exemplos como "abóbora" e "cócega", bem como seu diminutivo usual "xicrinha", o que reforça como tais ocorrências não são tão recentes quanto podem parecer para alguns falantes.

(11) xicras (AEAM-1790/fl.9v. 1.12 e fl.10r. 1. 21) 


\subsubsection{Síncope consonantal: "s"}

Outro caso de subtração, nesta ocasião, consonantal, é a do "s" em posição pós-vocálica. A eliminação do -s desinência de número é perceptível no português brasileiro moderno. No entanto, as alterações apresentadas não se configuram dessa maneira. De certo ponto de vista, essa eliminação pode ser considerada como uma acusação da palatalização do "t" antes de vogal alta anterior. A eliminação do "s" em sequências de sibilante + africada alveolopalatal no falar contemporâneo belo-horizontino é apresentada e discutida por Oliveira-Guimarães (2004), fenômeno que, atualmente, a ocorrência da palavra (13) "catesais" contempla, embora apenas tenhamos localizado um caso dessa natureza.

(12) sucretro (AEAM-1790/fl. 9v. 1. 5)

(13) catesais (AEAM-1790/fl. 9v. 1. 14)

\subsubsection{Síncope de semivogal: monotongação}

A monotongação dos ditongos ou, de forma sistemática exceto em fala cuidadosa, salvo os casos em que o ditongo é formado por ol, como "bolsa" e "golfo", ei antes de [r], [J] e [3], e ai antes de [J], é também apresentada por Viaro (2011, p. 138). As duas ocorrências de "caxa" no manuscrito sem a marcação do ditongo já evidenciam o fenômeno de monotongação do ai nesse ambiente, assim como as de "otro" e de "otra", que também demonstram a monotongação do ou.

Viaro (2011) também aponta para a possibilidade de monotongação em sílabas postônicas, apresentando como exemplo a palavra "órfão". No exemplo presente no manuscrito, a desinência -am é reduzida a -o, conforme "a Charo", o que evidencia que esse tipo de redução do ditongo e eliminação da nasalização, muitas vezes ouvido em falares do português brasileiro, já era produzido em fins do século XVIII.

(14) caxa (AEAM-1790/fl.9v. 1. 7, 16 e 17)

(15) hotro (AEAM-1790/fl.10r. 1. 32)

(16) hotra (AEAM-1790/fl.10v. 1.37 e 39)

(17) a Charo (AEAM-1790/fl.11r. 1. 8) 


\subsection{Transposições}

Referem-se à ocorrência de um mesmo segmento sonoro "num local distinto do encontrado no étimo." (Viaro, 2011, p. 159). Conforme o autor, há dois tipos de transposições: a metátese (referente a sons) e o hiperbibasmo (referente a acentos em fenômenos diacrônicos).

$\mathrm{O}$ autor também apresenta a variação entre as formas "oi” e "ou” e sua relação entre o ditongo latino "au". No texto, percebe-se a variação no uso dessas duas formas: "dous" "doirado(a)".

(18) doirado (AEAM-1790/fl.9v. 1. 8)

(19) doirada (AEAM-1790/fl.10r. 1. 26)

(20) dous (AEAM-1790/fl.10r. 1. 21)

\subsubsection{Metátese e hipértese}

Como metátese, Viaro apresenta o fenômeno de transposição de sons de uma posição a outra, em que muitas vezes o termo hipértese é utilizado para caracterizar a transposição específica de um som entre sílabas diferentes. Os casos de metátese e, consequentemente, de hipértese são caracterizados não só como motivados analogicamente, mas também estruturalmente. Para essa caracterização, o autor exemplifica casos em que a formação silábica $\mathrm{CrV}^{10}$ em sílaba postônica e $\mathrm{CV}$ em sílaba tônica é invertida. Desse modo, a nova sílaba tônica de estrutura CrV seria uma motivação de caráter enfático para a sílaba tônica. Em todos os casos da palavra (21), (22) e (23), que se refere a "sequestro", identificados no manuscrito, a formação $\mathrm{CrV}$ (s) na sílaba tônica é encontrada, o que valida a tonicidade da sílaba como influência para a manifestação da hipértese.

Casos de metátese, na própria sílaba, são observados em situações de deslocamento do " $r$ " para posição pós-vocálica em (24) e (25) "perzensiava(m)".

(21) s ocres atados (AEAM-1790/fl.11r. 1. 9)

(22) socrestado (AEAM-1790/fl.11r. 1. 12)

(23) sucrestos (AEAM-1790/fl.11r. 1. 13)

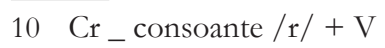

Mendes STP, Dores MVP, Gomes MF. Apontamentos paleográficos... 
(24) perzensiava (AEAM-1790/fl. 11v. 1. 25)

(25) perzensiaram (AEAM-1790/fl.11v. 1.25 e 26)

(26) sucrostos (AEAM-1790/fl.11v. 1. 26)

\subsection{Transformações}

Segundo Viaro, quando as transformações ocorrem de forma sistemática, a depender do grupo fônico envolvido nesse processo, são chamados de vocalismo ou consonantismo.

\subsubsection{Transformação vocálica: alçamento}

Ao definir alçamento como o fechamento de abertura de vogais em determinados ambientes, mais especificamente em posição pretônica, Viaro (2011, p. 167) exalta como é "o caso mais frequente em certas palavras do português brasileiro". De fato, entre todos os fenômenos encontrados na edição do manuscrito sob análise, o que se destaca com maior número de ocorrências é o de alçamento, conforme tabela abaixo:

Tabela 6 - Alçamento de vogais /o/ > /u/

\begin{tabular}{lll}
\hline & Itens $/ \mathbf{o} />/ \mathbf{u} /$ & Localização \\
\hline$(27)$ & Algudaõ & (AEAM-1790/fl.10r. 1. 29) \\
\hline$(28)$ & Buneco & (AEAM-1790/fl.10v. 1. 49) \\
\hline (29) & Butica & (AEAM-1790/fl.10v. 1. 37) \\
\hline$(30)$ & depuzitarão & (AEAM-1790/fl.11r. 1. 10) \\
\hline (31) & depuzitou & (AEAM-1790/fl.11r. 1. 9) \\
\hline (32) & muleque & (AEAM-1790/fl.10v. 1. 49) \\
\hline
\end{tabular}

Mendes STP, Dores MVP, Gomes MF. Apontamentos paleográficos... 
Tabela 7 - Alçamento de vogais /e/ > /i/

\begin{tabular}{|c|c|c|}
\hline & Itens $/ \mathrm{e} />/ \mathrm{i} /$ & Localização \\
\hline (33) & no miado & (AEAM-1790/fl.9v. 1. 4) \\
\hline (34) & piquenos & (AEAM-1790/fl.9v. 1.11 e fl.10v. 1. 45) \\
\hline (35) & piquenas & (AEAM-1790/fl.9v. 1. 6 e fl. 11r. 1. 5) \\
\hline$(36)$ & piquena & (AEAM-1790/fl.9v. 1.6 e 17, fl.10r. 20 e fl.11r. 1.7$)$ \\
\hline (37) & piqueno & (AEAM-1790/fl.9v. 1. 14) \\
\hline (38) & torniado & (AEAM-1790/fl.9v. 1. 10) \\
\hline (39) & trabiseiros & (AEAM-1790/fl.9v. 1. 9) \\
\hline
\end{tabular}

Tabela 8 - Alçamento de vogais /o/ > / u/ em "sucreto", "sucrestos" e "sucrostos"

\begin{tabular}{lll}
\hline$(40)$ & sucreto & $($ AEAM-1790/fl.9v. 1. 5) \\
\hline$(41)$ & sucrestos & $($ AEAM-1790/fl.11r. 1. 13) \\
\hline$(42)$ & sucrostos & $($ AEAM-1790/fl.11v. 1. 26) \\
\hline
\end{tabular}

Com relação aos dados da Tabela 8, chamamos a atenção para a seguinte questão: segundo o Dicionário etimológico da língua portuguesa (Cunha, 2010), a palavra em tela tem como origem a forma latina "sequestrāre", o autor também registra as ocorrências "socresto" e "socrestar" datadas respectivamente dos séculos XV e XVIII, formas que também são localizadas no manuscrito analisado: $s$ ocres atados (AEAM-1790/fl.11r. 1. 9) e (22) socrestado (AEAM-1790/fl.11r. 1. 12); isto posto, verifica-se um alçamento de "e" para "o". Mas, conforme os dados da Tabela 8, são apresentadas três ocorrências com a forma " $u$ ", indicando, então, outro alçamento de "o" para "u".

Também localizamos casos de abaixamento de vogal média/e/ para vogal baixa/a/, conforme:

(43) dazanove (AEAM-1790/fl.9v. 1. 8)

(44) lançoies (AEAM-1790/fl.10r. 1. 28)

Mendes STP, Dores MVP, Gomes MF. Apontamentos paleográficos... 
Entretanto, é preciso considerar que, conforme destaca Viaro, há palavras que foram grafadas em épocas bastante recuadas, e tomar a forma contemporânea para dizer que a estrutura localizada é um caso de alçamento pode ser um anacronismo. Para tanto, o autor apresenta o caso da grafia de minino que "já se encontrada grafada no século XIII (Cantigas de Santa Maria 323, v.40-4)", e o mesmo ocorre com "a forma piquena (século XV)"; ou seja, os casos (34 a 37) podem não ser alçamento.

Encontramos, ainda, nos dados analisados, palavras que apresentam uma vogal pretônica em posição oposta ao português brasileiro contemporâneo. Vogais posteriores grafadas com vogais anteriores e viceversa. Essa alternância pode ser considerada uma evidência da mudança na qualidade da vogal. Casos como "socretro", conforme apresentado anteriormente a partir da forma latina (grafada com /e/), e "velumes" demonstram essa transição. Destacamos também a ocorrência única do ditongo "eu" grafado como "eo" no caso de "deo", grafia comum na escrita até o início do século XX, conforme:

(45) deo (AEAM-1790/fl.11r. 1. 19)

(46) socres atados (AEAM-1790/fl.11r. 1. 9)

(47) socrestado (AEAM-1790/fl.11r. 1. 12)

(48) velume (AEAM-1790/fl.9v. 1. 9)

Localizamos, ainda, casos em que houve abaixamento da vogal /i/ $>/ \mathrm{e} /$, conforme tabela abaixo:

Tabela 9 - Abaixamento de vogais $/$ i/ $>/$ e/

\begin{tabular}{llc}
\hline & Itens $/ \mathbf{i} />/$ e & Localização \\
\hline$(49)$ & abreram & (AEAM-1790/fl.11v. 1. 24) \\
\hline$(50)$ & catesais & (AEAM-1790/fl.9v. 1. 14) \\
\hline$(51)$ & corteanados & (AEAM-1790/fl.10r. 1. 27) \\
\hline (52) & enteiro & (AEAM-1790/fl.10r. 1. 30) \\
\hline (53) & obregou & (AEAM-1790/fl.11r. 1. 13) \\
\hline
\end{tabular}




\subsubsection{Transformação consonantal}

Ainda segundo Viaro, embora haja exceções, a língua portuguesa de modo geral é bastante conservadora quanto à posição consonantal. De fato, no manuscrito localizamos poucos casos.

\subsubsection{Fortalecimento/Enfraquecimento}

Dois fenômenos de transformação consonantal apresentados por Viaro (2011, p. 173) ocorreram na passagem do latim ao português. O primeiro - de sonorização - ocorre quando consoantes surdas tornamse sonoras e o segundo diz respeito às consoantes oclusivas já sonoras tornarem-se fricativas. A assimilação de propriedades sonoras como enfraquecimento de um som menos sonoro próximo a vogais é conhecida amplamente devido à mudança do latim para as línguas românicas (Bybee, 2015).

Em relação à transformação de oclusivas em fricativas, a ocorrência de (54) "trabiseiros" com a letra "b" mostra não só o fortalecimento dessa forma, presente em regionalismos no Brasil, como esse dado mencionado e outros indicados pelo autor, como "[b]assoura", "[b]arrer", "[b]erruga" e "asso[b]iar" (Viaro, 2011, p. 174).

(54) trabiseiros (AEAM-1790/ f.9v. 1. 9)

\subsubsection{Vocalização}

Viaro (2011, p. 174) apresenta como frequente o processo de vocalização, em contraste com seu oposto, a consonantização. Como exemplo, o autor seleciona encontros consonantais em sílabas distintas, em que a estrutura formada por duas oclusivas tem a primeira vocalizada, como por exemplo a evolução latina captivum $>$ cautivo $>$ cativo. Uma estrutura idêntica, de formação -pt- $>$-ut- $>$ t é encontrada no vocábulo (55) "Bautismo". É possível definir a forma intermediária -ut- entre as formas grega -pt- e atual -t-.

(55) Bautismo (AEAM-1790/fl.10r. 1. 24) 
Muitos dos dados extraídos de um manuscrito do século XVIII, aqui apresentados, analisados e identificados no português contemporâneo, em especial o português brasileiro, demonstram como esse fenômeno de mudança fonética é bastante recorrente e atuante na língua.

\section{CONSIDERAÇÕES FINAIS}

O estudo de documentos pretéritos editados com critérios filológicos permite ao estudioso de Linguística Histórica pesquisar e dar a conhecer a história de sua língua, no caso em tela, da língua portuguesa. Foi possível verificar, mesmo que de forma parcial, tendo em vista os limites deste artigo, que muitos dos indícios de processos de mudança fonética para os quais o documento aponta ocorrem no português brasileiro contemporâneo. Para salientar alguns deles, vimos que o processo de alçamento de vogais foi um dos mais recorrentes, mas também constatamos um possível caso de registro de um consoante lateral / $1 /$ velar depois da vogal alta posterior /u/, provavelmente num caso de hipercorreção: [bauł].

\section{REFERÊNCIAS}

Bisol L. Os constituintes prosódicos. In: Bisol L, organizador. Introdução a estudos de fonologia do português brasileiro. 2. ${ }^{a}$ ed. Porto Alegre: EdiPUCRS; 1999. p. 229-241.

Bybee JL. Articulatory processing and frequency of use in sound change. In: Honeybone P, Salmons J, editors. The Oxford handbook of historical phonology. Oxford: Oxford University Press; 2015.

Cambraia CN. Introdução à crítica textual. São Paulo: Martins Fontes; 2005.

Cambraia $\mathrm{CN}$ et al. Normas para transcrição de documentos manuscritos para a história do português do Brasil. In: Silva RVM, organizador. Para a história do português brasileiro: primeiros estudos. São Paulo: Humanitas; 2001. p. 553-555. (Série Para a história do português brasileiro, vol. 2).

Carneiro MLT. Preconceito racial em Portugal e Brasil Colônia: os cristãos-novos e o mito da pureza de sangue. São Paulo: Perspectiva; 2005.

Chaves E. A implementação do pronome "você": a contribuição das pistas gráficas. [Dissertação]. Belo Horizonte: Faculdade de Letras, Universidade Federal de Minas Gerais; 2006.

Mendes STP, Dores MVP, Gomes MF. Apontamentos paleográficos... 
Coutinho IL. Pontos de gramática histórica. 7. ed. Rio de Janeiro: Ao Livro Técnico; 1976.

Cunha, AG. Dicionário etimológico da língua portuguesa. 4. a ed. Rio de Janeiro: Lexikon; 2010 .

Duchowny AT, Coelho SM, Coelho GH. Sistema de abreviaturas de documentos adamantinos setecentistas. Revista Letras. 2014;90:233-252. Disponível em: <http:// revistas.ufpr.br/letras/article/view/36430/23861>. Acesso em: 21 set. 2017.

Duchowny AT, Ramos JM, Coelho SM. Processos e mudanças em abreviaturas mineiras setecentistas: regularidade e ruptura. Filologia e Linguística Portuguesa. 2015;17(2):333352. Disponível em: <http://www.revistas.usp.br/flp/article/view/105407/111822>. Acesso em: 21 set. 2017.

Fachin PRM. Critérios de leitura de manuscritos: em busca de lições fidedignas. Filologia e Linguística Portuguesa. 2009;10-11:237-262. Disponível em: <https://www.revistas. usp.br/flp/article/view/59824/62933 >. Acesso em: 21 set. 2017.

Flexor MHO. Abreviaturas: manuscritos dos séculos XVI ao XIX. 3. a ed. Rio de Janeiro: Arquivo Nacional; 2008.

Oliveira-Guimarães DMLO. Variação nas seqüências de (sibilante + africada alveopalatal) no português falado em Belo Horizonte. [Dissertação]. Belo Horizonte: Faculdade de Letras, Universidade Federal de Minas Gerais; 2004.

Megale H, Toledo Neto SA, organizadores. Por minha letra e sinal: documentos do ouro do século XVII. São Paulo: Ateliê; 2005.

Mendes STP. Combinações lexicais restritas em manuscritos setecentistas de dupla concepção discursiva: escrita e oral. [Tese]. Belo Horizonte: Faculdade de Letras, Universidade Federal de Minas Gerais; 2008.

Spina S. Introdução à edótica: crítica textual. São Paulo: Cultrix; 1977.

Stiennon J. Paléographie du Moyen Âge. Paris: Armand Colin; 1973.

Viaro ME. Etimologia. São Paulo: Contexto; 2011.

Villalta LC. A Igreja, a sociedade e o clero. In: Resende MEL, Villalta LC, organizadores. História de Minas Gerais: as Minas setecentistas. Belo Horizonte: Autêntica; 2007. p. 2557. (Série História de Minas Gerais, vol. 2). 